\title{
The Impact of Transformational Leadership on the Helping Behavior of Hotel Employee
}

\author{
Wen-Chi Zou, Yong Zheng, and Jia Liu
}

\begin{abstract}
This study of 228 subordinates, 57 supervisors from five-star hotels demonstrated that transformational leadership has positive effect on leader-member exchange (LMX) , team-member exchange (TMX) and helping behavior. LMX and TMX partially mediated the relationship between transformational leadership and helping behavior. Implications for theory and practice are discussed and further research directions are offered.
\end{abstract}

Index Terms-Transformational leadership, leader-member exchange, team-member exchange, helping behavior.

\section{INTRODUCTION}

Nowadays, numerous previous studies have verified the positive effects of transformational leadership on follower's attitude, behaviors and performance [1]-[3]. Its effectiveness could be explained through the influence on follower's cognition, interpersonal relationship quality and cognition about the working environment and job.

Despite many researchers demonstrated the effectiveness of transformational leadership, rare studies explored how and why transformational leadership influences the behavior of followers through the quality of interpersonal relationship. Nowadays, few studies have examined the influence of transformational leadership on follower's one-to-one interpersonal relationship quality, such as leader-member exchange [4]. But the influence on follower's one-to-all interpersonal relationship quality such as team-member exchange hasn't been examined.

Accordingly, this study extends previous researches in this way. It employs social exchange theory [5], [6] and social learning theory [7] to explain how and why transformational leadership could influence followers' helping behavior toward coworkers through the quality of interpersonal relationships. Therefore, LMX and TXM function as the mediating roles, and follower's helping behavior toward coworkers has been regarded as the outcome because it illustrates the social exchange among group members [8].

\section{THEORY AND HYPOTHESIS}

Possakoff, MacKenzie, Moorman, \& Feeter [9] argued that leader could offer basic values, beliefs and attitudes to their followers and make them align with organization

Manuscript received October 11, 2013; revised December 26, 2013.

Yong Zheng is with the Beijing Normal University, Zhuhai, 18th Jinfeng Road, Tangjiawan, Zhuhai City, Guangdong Province, China (email: zhengyong2011@bnuz.edu.cn). collective interests. Transformational leadership has been defined from six dimensions. To articulate vision of organization's future; To act as a role model consistent with that vision; To express high performance expectation to their subordinates; To convince their subordinates of heir group goals; To provide individual support and intellectual stimulation [4].

Helping behavior involves voluntarily helping others with, or preventing the occurrence of, work-related problems. It includes OCB dimensions of Organ's (altruism, courtesy, peacemaking, and cheerleading) and OCB-I of Williams \& Anderson [10]-[12].

\section{A. Transformational Leadership and Helping Behavior}

Transformational leader enhance the follower's confidence by expressing their high expectations; cultivate followers' capabilities via offering constructive feedback and advices for their development; encourage followers to apply new methods to solve the working problems; reward followers by praising their working skills and performance. Such behaviors make the followers realize the transformational leader's caring and support which tighten their bond of affection. In terms of social learning theory [7], transformational leader act as role model for the followers to learn and imitate. Likewise, the followers would mimic these behaviors and help the other group members. In addition, from the perspective of social exchange theory and norm of reciprocity [5], [6], followers may help other group members achieve group goal, as reciprocity for transformational leader's support.

Transformational leadership also transmits to the followers the group identity by expressing the honor of group's achievement and inspires followers to accept the vision and collective goals by articulating an attractive picture of the group's future. These behaviors could help followers understand the vision of organization and share common interests. Thus, it's reasonable to predict that transformational leader can strengthen the cohesion of group and make followers demonstrate more extra-role behaviors, such as helping coworkers. Scholars also found transformational leader has positive effect on follower's helping behavior toward team members [13], [14]. Hence, we predict:

Hypothesis 1): Transformational leadership is positively related to follower's helping behavior toward coworkers.

\section{B. Transformational Leadership, LMX and TMX}

Scholars argued that different behaviors of transformational leadership have influence on different aspects of followers' self-concept, especially, transformational leadership process are most relevant on collective identity [15] and relational identity [3]. 
Relationship identity derived from dyadic connection and role relationship with significant others. At this level follower's behaviors are driven by self-interest as well as specific other's interest, and self-worth is comes from appropriate role behaviors. Besides, follower who adopts a relation identity will rely on the norm or reciprocity to facilitate their exchange [6] and prefers reciprocal exchange with the ones who are in the role relationship [16], [17]. Collective identity makes follower define himself/herself by social group memberships, where favorable intergroup comparisons give rise to self-worth. At this level, follower's behaviors are motivated by group interest which they belong and preferred generalized exchange with the other group members [16], [17].

Transformational leadership will develop follower's relational identity by interpersonal interaction ways [3], [18], such that communicating high expectations, follower development, intellectual stimulation, and personal recognition. The series behaviors of caring and support from transformational leader enable follower relational identify such leader and reciprocate the leader through work hard, show trust and respect to leader. Consequently, high quality relationships between leader and follower emerge. The empirical research of Wang et al. [4] also supports the argument. Thus, we hypothesize:

Hypothesis 2a): Transformational leadership is positively related to LMX.

When transformational leader demonstrates that emphasizing group identity, articulating group vision, and team-building to the followers. The followers' self-concept has been changed from personal to collective and the definition shift from "I" to "We". Consequently, followers accept the group values norms and goals. Meanwhile, group interest and success have been regard as self-interest and personal success by followers. These make followers have common interest and shared values, and facilitate them help the other coworkers in the work, offer constructive feedback and improving advices, trust and respect other coworkers working abilities [19]. In turn, the other coworkers are willing to reciprocate the same to group members. These series of social exchange among followers represent the characteristics of generalized exchange [17]. Generalized exchange is one of critical characteristics of TMX which patterns of reciprocation develop across a group of followers [20]. Therefore, we proposed that transformational leadership could help follower build collective identity, meanwhile, this identity make follower develop high quality relationships with the other coworkers.

Hypothesis 2b): Transformational leadership is positively related to TMX.

\section{Mediating Roles of LMX and TMX}

LMX and TMX represent the social exchange and reciprocity among group members [19], [21]. It includes the exchange of intrinsic benefit such as acceptance, trust, and external benefit such as advice and assistance [5]. And one who has received these could follow the norms of reciprocity and do the favor as payback [6]. Therefore, when the follower has high quality relationship with the leader and coworkers, he/she will more helping behaviors in order to maintain the relationship. In addition, empirical researches also provide the support on the positive influence of LMX and TMX on follower's helping behavior toward coworkers [13], [22]. In sum, we proposed that LMX and TMX, plays as the mediating role between transformational leadership and helping behavior. We hypothesize:

Hypothesis 3a): LMX mediates the relationship between transformational leadership and helping behavior toward coworkers.

Hypothesis 3b): TMX mediates the relationship between transformational leadership and helping behavior toward coworkers.

\section{SAMPLE AND PROCEDURE}

The dyadic data used to test our hypothesis have been collected from five-star hotels in south China. The supervisor evaluates the helping behavior of the subordinates. The subordinates evaluate transformational leadership of the supervisor, and relationship quality with the supervisor and coworkers.

After deleting individuals with missing information and the ones who fail in finishing the whole survey, we got final usable samples include 57 supervisors and 228 followers (average group size is 4). In the sample of 57 supervisors, 71 percent were male, mean age was 30.6 years, and mean organizational tenure was 7 years. Among the new employees, 52 percent were male, mean age was 22.3 years. Over 84 percent held college diploma or higher degree.

\section{MEASURES}

We used Likert-type scales to assess all items. Response of other scales ranging from 1 "strongly disagree" to 5 "strongly agree". Except transformational leadership scale, the other original scales are all of English version; they were translated into Chinese from English following the standard translation and back-translation procedures [23]. Transformational leadership style was assessed by 23 items adopted from Chen \& Farh scale [24]. It has been validated in previous studies, such as Wang et al [4]. Leader-member exchange was used the LMX-MDM [25] to measure leadermember exchange. Sample item is "My supervisor is kind of person one who would like have as a friend." Team-member exchange was measured with 10 items from Seers, Petty, \& Cashman [19]. Sample item is "Other members of team understand my problems and needs". Helping behaviors was measured with 6 items from Williams and Anderson's [12]. Sample item is" He/She helps others who have been absent."

\section{RESULTS}

\section{A. Confirmatory Factor Analysis}

We used LISREL 8.70 [26] to conduct confirmatory factor analyses. To form the measurement models, we randomly created three indicators of items each for TMX and helping behavior. For transformational leadership, we used six dimensions as its indicators. LMX also be used four dimensions as its indicators. The hypothesized fourfactor model consisting of four factors (transformational 
leadership, LMX, TMX, helping behavior) fit the data well. We compared the hypothesized four-factor model with other alternative measurement modes. From Table I, the results showed evidence of the construct distinctiveness and revealed that the same source variance didn't impact measure validity.

TABLE I: COMPARISON OF MEASUREMENT MODELS

\begin{tabular}{llllllll}
\hline Model & Factors & $\chi^{2}$ & $d f$ & $\Delta \chi^{2}$ & RMSEA TLI & CFI \\
\hline Baseline model & Four factors & 292.61 & 98 & & 0.07 & 0.92 & 0.94 \\
Model 1 & Three factors 432.49 & 101 & $139.88^{* *}$ & 0.13 & 0.87 & 0.89 \\
Model 2 & Two factors & 493.52 & 103 & $200.91^{* *}$ & 0.16 & 0.85 & 0.86
\end{tabular}

Model 1: LMX and TMX were combined into one factor;

Model 2: LMX, TMX and helping behavior were combined together;

* $P<0.05 ; * * P<0.01$

\section{B. Hypothesis Tests}

Table II presents the means, standard deviations, correlations and reliabilities for all of the variables. In line with our hypothesis, transformational leadership is positively related to LMX, TMX and helping behavior, LMX and TMX are positively related to helping behavior respectively.

TABLE II: MEANS, STANDARD DEVIATIONS, AND INTERCORRELATIONS AMONG VARIABLES

\begin{tabular}{lcccccc}
\hline Variables & $M$ & $S D$ & 1 & 2 & 3 & 4 \\
\hline 1. Transformational leadership & 3.63 & 0.75 & $(0.92)$ & & & \\
2. TMX & 3.74 & 0.81 & $0.24^{*}$ & $(0.87)$ & & \\
3. LMX & 4.08 & 0.59 & $0.32^{*}$ & 0.12 & $(0.85)$ \\
4. Helping behavior & 3.82 & 0.75 & $0.40^{* *}$ & $0.49^{* *}$ & $0.38^{* *}$ & $(0.79)$ \\
\hline
\end{tabular}

$* P<0.05, * * P<0.01 . N=228$; reliability coefficients for the scales are in parentheses along the diagonal.

Table III shows the comparison of model fitness among baseline model, nested model and alternative model. Model 1 is baseline model, representing a full mediating model. We specified paths from transformational leadership to LXM and TMX, and also specified the paths from LXM and TMX to helping behavior. Against the baseline model, we tested one nested models. In model 2 , we added a directed path from transformational leadership to helping behavior. Model 1 is nested within models 2. As Table III shows, the differences between chi-square were significant for model 1 compared with model 2 . The results indicated that model 2 fitted the data best. Model 3, 4 are alternative models that are not nested within the above two models. We added the alternative models to assess the effects of changing construct ordering. Model 3, 4 are not fit the data.

From Table III and Fig. 1, the results of structure equation modelling analysis reveal that transformational leadership has positive effect on LMX and TMX. LMX and TMX positive associate with helping behavior respectively. Meanwhile, LMX and TMX partially mediated the relationship between transformational leadership and helping behavior.

TABLE III: COMPARISON OF STRUCTURAL EQUATION MODELS

\begin{tabular}{lcccccc}
\hline Model and Structure & $\chi^{2}$ & $d f$ & $\Delta \chi^{2}$ & RMSEA & TLI & CFI \\
\hline 1. $\mathrm{TFL} \rightarrow \mathrm{TMX}+\mathrm{LMX} \rightarrow \mathrm{HB}^{\mathrm{a}}{ }^{3} 348.42$ & 100 & 0.08 & 0.92 & 0.93 \\
2. $\mathrm{TFL} \rightarrow \mathrm{TMX}+\mathrm{LMX} \rightarrow \mathrm{HB}$ & 326.57 & 99 & $21.85^{* *}$ & 0.07 & 0.93 & 0.94 \\
$\mathrm{TFL} \rightarrow \mathrm{HB}$ & & & & & & \\
3. $\mathrm{HB} \rightarrow \mathrm{TMX}+\mathrm{LMX} \rightarrow \mathrm{TFL}$ & 472.28 & 100 & $123.86^{* *}$ & 0.13 & 0.87 & 0.88 \\
4. $\mathrm{TFL} \rightarrow \mathrm{HB} \rightarrow \mathrm{TMX}+\mathrm{LMX}$ & 401.66 & 100 & $53.24^{* *}$ & 0.11 & 0.88 & 0.90
\end{tabular}

a. Baseline model; $\mathrm{TFL}=$ transformational leadership; $\mathrm{TMX}=$ teammember exchange; LMX= leader-member exchange; $\mathrm{HB}=$ helping behavior; " $\rightarrow$ " model path; ** $P<0.01$.

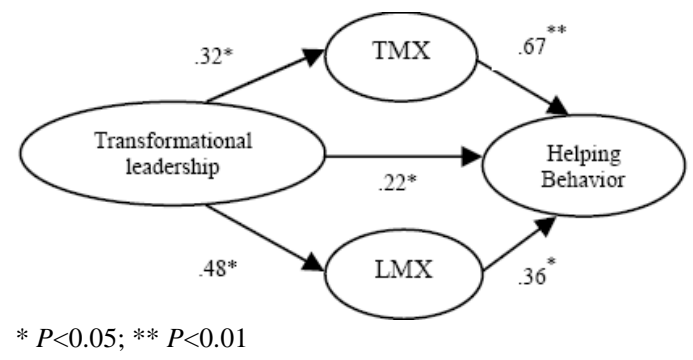

Fig. 1. Results of structural equation modeling on the mediating effect.

\section{DISCUSSION}

This study examined models linking of transformational leader to helping behavior by using LMX and TMX as two mediators. The results showed that LMX and TMX partially mediated the relationship between transformational leadership and helping behavior. The conclusion reveals that the effectiveness of transformational leadership on the behavior of followers through the quality of interpersonal relationship. It suggests that transformational leader is best candidate as agent of organization, beside, managers can be trained to develop this kind of leadership style. LMX and TMX as two core interpersonal relationships, and build high quality relationship among group members is one of effective way to enhance contextual performance. Thus, organization and managers should via some ways, such as giving the sense and significance of followers' work, caring the benefits of the followers. It can help group members identify with their organization and managers and enhance their relationship quality with other group members and supervisors.

This study was conducted within single industry of hospitality in the context of Chinese culture. Further researches should extend these findings to other industries in order to enhance its generalizability. Additionally, this study didn't take into consideration of the influence of individual characteristics, such as reciprocity belief. Thus, a further extension of our model is to include follower's character and examine whether it could influence the social exchange of followers

\section{REFERENCES}

[1] U. R. Dumdum, K. B. Lowe, and B. J. Avolio, “A meta-analysis of transformational and transactional leadership correlates of 
effectiveness and satisfaction: An update and extension," in Transformational and Charismatic Leadership: The Road Ahead, B. J. Avolio and F. J. Yammarino (Eds.), Oxford: Elsevier Science, vol. 2, pp. 35-66, 2002.

[2] T. A. Judge and R. Piccolo, "Transformational and transactional leadership: A meta-analytic test of their relative validity," Journal of Applied Psychology, vol. 89, no. 5, pp. 755-768, 2004.

[3] F. O. Walumbwa and C. A. Hartnell, "Understanding transformational leadership-employee performance links: The role of relationsl identification and self-efficacy," Journal of Occupational and Organizational Psychology, vol. 84, no. 1, pp. 53-172, 2011.

[4] H. Wang, K. S. Law, R. D. Hackett, D. X. Wang, and Z. X. Chen, "Leader-member exchange as a mediator of the Relationship between transformational leadership and follower's Performance and Organizational citizenship Behavior," Academy of Management Journal, vol. 48, no. 3, pp. 420-432, 2005.

[5] P. M. Blau, Exchange and Power in Social Life, New York: John Wiley, 1964

[6] W. Gouldner, "The norm of reciprocity," American Sociological Review, vol. 25, pp. 161-78, 1960.

[7] A. Bandura, Social Learning Theory, Englewood Clivs, NJ: PrenticeHall, 1977.

[8] R. T. Sparrow, B. W. Soetjito, and M. L. Kramer, "Do leaders' influence tactics relate to members' helping behavior? It depends on the quality of the relationship," Academy of Management Journal, vol. 49, no. 6, pp. 1194-1208, 2006.

[9] P. M. Podsakoff, S. B. MacKenzie, R. H., Moorman, and R. Fetter, "Transformational leader behaviors and their effects on followers' trust in leader, satisfaction, and organizational citizenship behavior," The Leadership Quarterly, vol. 1, no. 2, pp. 107-142, 1990.

[10] D. W. Organ, Organizational Citizenship Behavior: The Good Soldier Syndrome, Lexington, MA: Lexington Books, 1988.

[11] P. M. Podsakoff, S. B. MacKenzie, J. B. Paine, and D. G. Bachrach, "Organizational citizenship behaviors: A critical review of the theoretical and empirical literature and suggestions for future research," Journal of Management, vol. 26, no. 3, pp. 513-563, 2000.

[12] L. J. Williams and S. E. Anderson, "Job satisfaction and organizational commitment as predictors of organizational citizenship and in-role behaviors," Journal of Management, vol. 17, no. 3, pp. 601-617, 1991

[13] D. Kamdar and L. V. Dyne, "The Joint effects of personality and workplace social exchange relationship in predicting task performance and citizenship Performance," Journal of Applied Psychology, vol. 92, no.5, pp. 1286-1298, 2007.

[14] X. H. F. Wang and J. M. Howell, "Exploring the dual-level effects of transformational leadership on followers," Journal of Applied Psychology, vol. 95, no. 6, pp. 1134-1144, 2010.

[15] R. Kark, B. Shamir, and G. Chen, "Two faces of transformational leadership: Empowerment and dependency," Journal of Applied Psychology, vol. 88, no. 2, pp. 246-255, 2003.
[16] M. B. Brewer and W. Gardner, "Who is this "we'? Levels of collective identity and self-representations," Journal of Personality and Social Psychology, vol. 71, no.1, pp. 83-93, 1996.

[17] F. J. Flynn, "Identity orientation and forms of social exchange in organization," Academy of Management Review, vol. 30, no. 4, pp. 737-750, 2005.

[18] D. M. Sluss and B. E. Ashforth "Ashforth, relational identity and identification: Defining ourselves through work relationships," Academy of Management Review, vol. 32, no. 1, pp. 9-32, 2007.

[19] A. Seers, M. M. Petty, and J. F. Cashman, "Team-member exchange under team and traditional management: A naturally occurring quasiexperiment," Group and Organization Management, vol. 20, no.1, pp. $18-38,1995$.

[20] L. Keup, N. S. Bruning, and A. Seers, "Member, Leaders and the team: Extending leader-member exchange to co-worker relationships," presented at the Administrative Sciences Association of Canada, Quebec, 2004.

[21] G. B. Graen and M. U. Bien, "Relationship-based approach to leadership: Development of leader-member exchange (LMX) theory of leadership over 25 years: Applying a multi-level multi-domain perspective," Leadership Quarterly, vol. 6, pp. 219-247, 1995.

[22] R. Ilies, J. D. Nahrgang, and F. P. Morgeson, "Leader-member exchange and citizenship behaviors: A meta-analysis," Journal of Applied Psychology, vol. 92, no. 1, pp. 269-277, 2007.

[23] R. W. Brislin, "The wording and translation of research instruments," in Field Methods in Cross-Cultural Research, W. J. Lonner and J. W. Berry (Eds.), Beverly Hills, CA: Sage, pp. 137-164, 1986.

[24] X. P. Chen and J. L. Farh, "The effectiveness of transactional and transformational leader behaviors in Chinese organizations: Evidence from Taiwan," Annual Academy of Management Meeting, Chicago, 1999.

[25] R. C. Liden and J. M. Maslyn, "Multi-dimensionality of leadermember exchange: An empirical assessment through scale development," Journal of Management, vol. 24, no. 1, pp. 43-72, 1998.

[26] K. G. Jöreskog and D. Sörbom, "LISREL 8.70," Scientific Software International, 2004

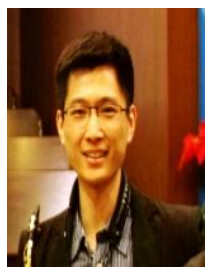

Wenchi Zou was born in Shenyang city, China, on September 15, 1980. He received his Ph.D. in organizational behavior from the Macau University of Science and Technology in 2010. In the same year, he has been working in the Macau University of Science and Technology as assistant professor. His research and academic teaching focus on organizational behavior and hospitality management. 